\title{
Acquired Factor VIII Inhibitor in a Non-Hemophilic Patient with Chronic Hepatitis C Viral Infection
}

\author{
Kazuro Sugishita, Hiroyuki Nagase, Toshiyuki Takahashi, Katsu Takenaka, \\ Yasushi SHIRATORI and Masao OMATA
}

\begin{abstract}
Production of coagulation factor VIII inhibitor is rarely encountered in non-hemophilic patients. A 63-year-old Japanese male suffered from severe bleeding tendency caused by this inhibitor. Although he did not have malignancy or collagen disease, he had chronic hepatitis $\mathrm{C}$ virus (HCV) infection. Although HCV is known to induce production of various autoimmune antibodies, this may be the first report of a case with both acquired factor VIII inhibitor and HCV infection.
\end{abstract}

(Internal Medicine 38: 283-286, 1999)

Key words: steroid pulse therapy, plasmapheresis

\section{Introduction}

Coagulation factor VIII inhibitor is often produced in hemophilic patients who frequently receive transfusion of this factor. However, this inhibitor is rarely found in non-hemophilic patients. In the reviews of the non-hemophilic patients with the inhibitor, some cases were shown to have underlying disorders (postpartum, malignancy or collagen diseases), which may have induced immunological disorders and autoimmune antibodies $(1,2)$. In contrast, the majority of the patients with the inhibitor had no apparent underlying diseases and were then considered to be "idiopathic". On the other hand, hepatitis C virus $(\mathrm{HCV})$ infection is known to be associated with various immunological disorders or autoimmune antibodies (3). Green and Lechner reported two cases with factor VIII inhibitor who had hepatitis, but the etiology of the liver dysfunction was not described (1). We treated a non-hemophilic patient with factor VIII inhibitor and HCV antibody. This may be the first report of such a case presenting both antibodies.

\section{Case Report}

A 63-year-old Japanese male was admitted to our department because of a severe bleeding tendency. He had a history of atherosclerotic occlusions in bilateral femoral arteries and angina pectoris. At the age of 57, he was initially diagnosed to have chronic hepatitis; his prothrombin time (PT) was low nor- mal (70\% of the control value) and his activated partial thromboplastin time (APTT) was slightly prolonged (38.8-40.1 second). One month before admission, hematoma appeared in his oral cavity, and purpura on the left side of his neck. Five days after the onset, hematoma appeared also in his right groin area. Laboratory data showed almost normal PT (PT-INR 1.26), prolonged APTT (55.4 second) and severe anemia (hemoglobin $6.0 \mathrm{~g} / \mathrm{dl})$. After anti-platelet agents were discontinued, anemia improved gradually (hemoglobin $11.0 \mathrm{~g} / \mathrm{dl}$ ). However, at one month after the onset of hemorrhagic episodes, he suddenly experienced severe lumbar-back pain. As the pain became worse, he visited the emergency unit of our hospital. At the visit, he showed hypotension $(70 \mathrm{mmHg}$ ) and severe anemia (hemoglobin $6.3 \mathrm{~g} / \mathrm{dl}$ ). Hematoma was detected in his retroperitoneal area by ultrasonography as well as computed tomography. Under the diagnosis of hypovolemic shock caused by retroperitoneal hemorrhage, he was admitted to our department.

On admission, physical examination revealed old purpurae on his neck and right femoral region, anemic conjunctivae, palmar erythema and clubbed fingers. Laboratory data showed severe normocytic, normochromic anemia (Table 1). Neither rheumatoid factor nor antinuclear antibody was detected, although C-reactive protein (CRP) value was increased. He was positive for HCV antibody, with a viral titer of $10^{5.5}$ copies/50 $\mu \mathrm{l}$ by competitive RT-PCR. The subtype of his HCV was classified as lb. Coagulation tests showed mildly prolonged PT (INR 1.47)

From the Second Department of Internal Medicine, Faculty of Medicine, University of Tokyo, Tokyo

Received for publication June 3, 1998; Accepted for publication November 9, 1998

Reprint requests should be addressed to Dr. Kazuro Sugishita, the Second Department of Internal Medicine, University of Tokyo, 7-3-1 Hongo, Bunkyo-ku, Tokyo 113-8655 
Sugishita et al

Table 1. Laboratory Data on Admission

\begin{tabular}{llll}
\hline Blood cell count: & $13.7 \times 10^{3} / \mu \mathrm{l}$ & Blood Chemistry & \\
White blood cell & $190 \times 10^{4} / \mu \mathrm{l}$ & Total protein & $7.7 \mathrm{~g} / \mathrm{dl}$ \\
Red blood cell & $6.3 \mathrm{~g} / \mathrm{dl}$ & Albumin & $3.8 \mathrm{~g} / \mathrm{dl}$ \\
Hemoglobin & $19.7 \%$ & AST & $18 \mathrm{IU} / l$ \\
Hematocrit & $33 \% 0$ & ALT & $16 \mathrm{IU} / \mathrm{l}$ \\
Reticulocyte & $21.2 \times 10^{4} / \mu \mathrm{l}$ & Lactate dehydrogenase & $141 \mathrm{IU} / l$ \\
Platelet & & Alkaline phosphatase & $147 \mathrm{IU} / l$ \\
Serological: & $2.0 \mathrm{mg} / \mathrm{dl}$ & Total bilirubin & $0.9 \mathrm{mg} / \mathrm{dl}$ \\
C-reactive protein & $(3+)$ & Blood urea nitrogen & $23 \mathrm{mg} / \mathrm{dl}$ \\
Hepatitis C virus-Ab & $10^{5.5}$ copies $/ 50 \mu l$, subtype lb & Creatinine & $1.7 \mathrm{mg} / \mathrm{dl}$ \\
Hepatitis C virus-RNA & $(-)$ & Na & $137 \mathrm{mEq} / l$ \\
HBsAg & & $\mathrm{K}$ & $5.5 \mathrm{mEq} / l$ \\
Urinalysis: & 1.030 & Cl & $104 \mathrm{mEq} / l$ \\
SG & 5.0 & Glucose & $231 \mathrm{mg} / \mathrm{dl}$ \\
pH & $(1+)$ & & \\
Pro & $(+-)$ & Coagulation factor activities & \\
Glu & $(+-)$ & II & $69 \%(62-127)$ \\
OB & & V & $85 \%(50-150)$ \\
Coagulation test (normal ranges): & $14.3 \mathrm{sec}$ & VII & $49 \%(65-135)$ \\
Prothrombin time & $1.47(0.951-1.15)$ & VIII & $7 \%(50-150)$ \\
PT-INR & $56.9 \mathrm{sec}(27-37)$ & IX & $102 \%(60-140)$ \\
APTT & $205 \mathrm{mg} / \mathrm{dl}(210-310)$ & X & $66 \%(56-138)$ \\
Fibrinogen & $12 \mathrm{Bethesda} \mathrm{units/ml}$ & XI & $48 \%(65-135)$ \\
Factor VIII inhibitor & $(-)$ & XII & $142 \%(50-150)$ \\
Factor IX inhibitor & $75 \%(77.6-123.1)$ & XIII & $56 \%(70-140)$ \\
AT-III & & vWF* & $232 \%(60-170)$ \\
& & &
\end{tabular}

HBsAg: hepatitis B virus surface antigen, APTT: activated partial thromboplastin time, AST: aspartate aminotransferase, ALT: alanine aminotransferase, ${ }^{*} \mathrm{vWF}$ : von Willebrand factor.
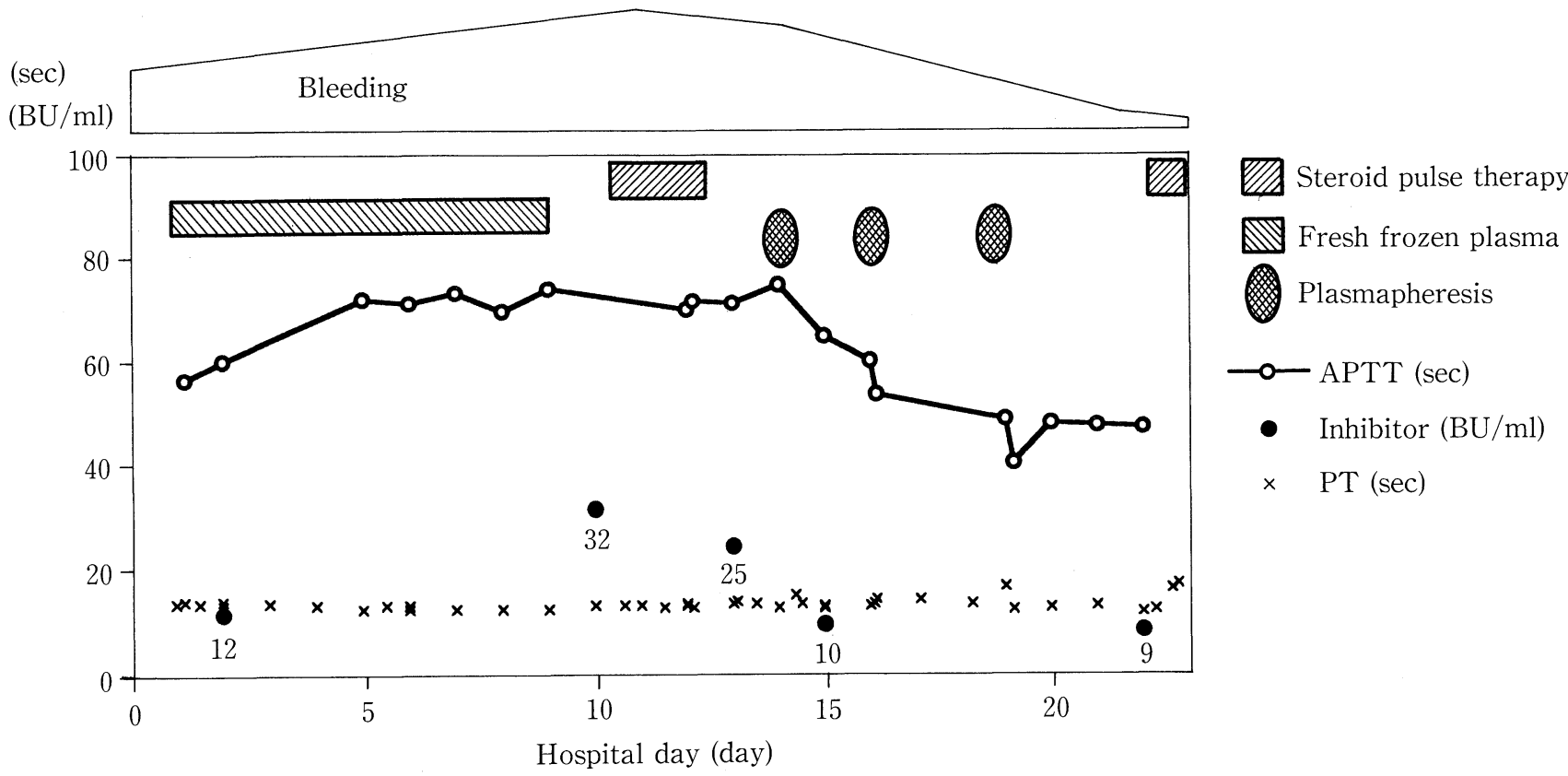

Figure 1. Clinical course after admission. APTT: activated partial thromboplastin time measured with soybean-derived cephalin (DADE FS ${ }^{\circledR}$, Dade International Inc., Miami, FL, USA), Inhibitor: factor VIII inhibitor, BU: Bethesda units, PT: prothrombin time. 
and prolonged APTT (56.9 second) (Table 1). The level of plasma fibrinogen was low $(205 \mathrm{mg} / \mathrm{dl})$, whereas that of fibrinogen degradation product (FDP) remained normal $(1.5 \mu \mathrm{g} / \mathrm{ml})$. His clinical course after admission is illustrated in Fig. 1. Briefly, repeated blood transfusion transiently improved his anemia and hypotension, but fresh frozen plasma transfusion failed to control the bleeding tendency itself. He experienced repetitive severe hemorrhagic episodes, including right hemothorax, intramuscular bleeding in his right biceps, macrohematuria, subcutaneous bleeding on the left side of his abdominal wall and bloody stool. On the 10th hospital day, a marked decrease in the activity of coagulation factor VIII (7\% of the control) was found and the concentration of factor VIII inhibitor was elevated to 12 Bethesda units/ml (Table 1). The activities of some of the other coagulation factors (II, VII, X, XI, XII) were also slightly decreased or at lower normal ranges, presumably because of liver dysfunction. According to these data, we suspected that his bleeding tendency was mainly caused by the acquired factor VIII inhibitor. Thus, we started steroid pulse therapy using methylprednisolone $1 \mathrm{~g} /$ day for 3 days to correct his coagulation abnormalities. Unfortunately, the effect of this therapy was insufficient as his APTT was shortened only from 74.6 second to 65.4 second. Subsequently, we performed plasmapheresis on the 14th hospital day and his APTT value was significantly abbreviated to 53.9 second. As the oozing from the site of catheter insertion was not well controlled, we repeated this procedure twice on the 16th and 19th hospital days. His APTT further improved to 40.9 second, but the oozing from the catheter site continued. This situation led us to perform a second steroid pulse therapy on the 22nd hospital day. On the evening of the day of the steroid therapy, when his APTT value was 47.8 second, severe upper abdominal pain occurred suddenly. As his abdomen was distended with no bowel sound, paralytic subileus was suspected. Hematoma was not detected with ultrasonography, and there was no change in his hemoglobin level $(9.0 \mathrm{~g} / \mathrm{dl})$. His condition rapidly deteriorated despite supportive therapies, and he died of multiple organ failure on the following day. The level of factor VIII inhibitor remained high (9 Bethesda units $/ \mathrm{ml}$ ) on the day of the second steroid pulse therapy.

Autopsy revealed multiple old hematomae, as detected before his death, and liver cirrhosis of the mesonodular type. Ischemic necrosis of the ileum (length of $50 \mathrm{~cm}$ ) was found, and his superior mesenteric artery was compressed by massive retroperitoneal hematoma. Microthrombi, which are specific for disseminated intravascular coagulation, were not detected.

\section{Discussion}

Production of factor VIII inhibitor is seldom seen in nonhemophilic patients. The mechanism of the acquired factor VIII inhibitor production has not yet been clarified in non-hemophilic patients. Some underlying pathophysiological states, including collagen and autoimmune diseases, pregnancy, and malignancy, have been reported, and these conditions are known to induce immunological disorders and autoimmune antibod- ies. In contrast, about half of the patients with the acquired factor VIII inhibitor were considered as idiopathic $(1,2)$. The present patient did not have major underlying disorders, except for liver dysfunction caused by HCV infection. We diagnosed his liver dysfunction as chronic hepatitis $\mathrm{C}$ before his death because of his history of mild elevation of transaminases for more than 6 months, but pathological examination revealed typical cirrhotic changes in his liver. Earlier reports demonstrated that a few of patients with factor VIII inhibitor had hepatic diseases $(1,4,5)$. Green and Lechner showed that two patients were associated with hepatitis out of 215 cases with the inhibitor, but the etiology or severity of their chronic liver disease was not evaluated (1). Uoshima et al reported a 61year-old Japanese male with non-B liver cirrhosis and esophageal varices, who suffered from gingival bleeding and subcutaneous hematoma caused by factor VIII inhibitor (4). On admission, his antinuclear antibody, thyroid test and microsome test were positive, but they became negative along with the recovery of his coagulation function due to steroid and immunosuppressive therapies. Neilson et al reported that a non-hemophilic male with the factor VIII inhibitor was associated with non-B non-C liver cirrhosis and hepatocellular carcinoma (5). His titer of the inhibitor was very high (435 Bethesda units $/ \mathrm{ml}$ ) and he died of hepatic failure. In spite of these earlier reports concerning the association of the factor VIII inhibitor and liver diseases, there has been no report of a non-hemophilic patient demonstrating both the factor VIII inhibitor and HCV antibody.

$\mathrm{HCV}$ has been reported to be associated with various immunological disorders (3). It is well known that some types of cryoglobulinemia are related to HCV infection (6), and glomerulonephritis without cryoglobulinemia has also been reported to be accompanied with $\mathrm{HCV}$ infection (7). In addition, a high prevalence of rheumatoid factor was reported in HCVpositive patients (8), although its immunological role is not yet well understood. On the other hand, many patients with chronic hepatitis $\mathrm{C}$ have sialoadenitis like sicca syndrome (9). Furthermore, liver/kidney microsomal (LKM) autoantibody, one of the specific markers of autoimmune hepatitis (type II), has often been detected in HCV RNA-positive patients without autoimmune hepatitis (10). Other autoantibodies, including anti-GOR, smooth muscle antibody and antinuclear antibody, are also reported to be more frequently detected in HCVpositive patients than in HCV-negative patients (11).

The combination of the therapeutic measures usually induces disappearance of the factor VIII inhibitor or control of bleeding tendency in patients with the acquired inhibitor. In contrast, despite plasmapheresis and steroid pulse therapy, the levels of factor VIII inhibitor remained high and the bleeding tendency was not completely controlled in the present case. At autopsy, his superior mesenteric artery was compressed by a massive retroperitoneal hematoma, and this compression was suspected to be responsible for the ischemic necrosis of the ileum. These pathologic findings also suggest that the control of coagulation abnormalities attained in this patient was insufficient for complete prevention of fatal bleeding episodes.

Production of the coagulation factor VIII inhibitor and HCV 


\section{Sugishita et al}

infection are known as serious complications of blood transfusion therapy to patients with congenital hemophilia A (12). In contrast, the association of the factor VIII inhibitor and HCV antibody in non-hemophilic patients is not well recognized and its molecular mechanisms remain to be elucidated. As discussed earlier, the changes in immunological systems induced by HCV infection may be responsible for the inhibitor production, although there is no direct evidence of immunological crossover between the factor VIII inhibitor and HCV antibody.

We reported a non-hemophilic case demonstrating both factor VIII inhibitor production and HCV infection. Although the direct relationship between these two events remains to be elucidated, it may be possible that this inhibitor was produced as a result of the immunological disturbances evoked by $\mathrm{HCV}$ infection.

\section{References}

1) Green D, Lechner K. A survey of 215 non-hemophilic patients with inhibitors to Factor VIII. Thromb Haemost 45: 200-203, 1981.

2) Kessler CM, Ludlam CA, and International Acquired Hemophilia Study Group. The treatment of acquired factor VIII inhibitors: worldwide experience with porcine factor VIII concentrate. Semin Hematol 30: 22-27,
1993.

3) Gumber SC, Chopra S. Hepatitis C: a multifaceted disease. Review of extrahepatic manifestations. Ann Intern Med 123: 615-620, 1995.

4) Uoshima N, Ootuki R, Hiramori N, et al. A case of liver cirrhosis with acquired factor VIII inhibitor. Kyoto Daini Seki-juji Byoin lgaku Zasshi 10: 187-193, 1989 (Abstract in English).

5) Neilson RF, Walker ID, Robertson M. Factor VIII inhibitor associated with hepatocellular carcinoma. Clin Lab Haematol 15: 145-148, 1993.

6) Agnello V. The etiology and pathophysiology of mixed cryoglobulinemia secondary to hepatitis $C$ virus infection. Springer Semin Immunopathol 19: 111-129, 1997

7) Cosio FG, Roche Z, Agarwal A, Falkenhain ME, Sedmak DD, Ferguson RM. Prevalence of hepatitis $C$ in patients with idiopathic glomerulopathies in native and transplant kidneys. Am J Kidney Dis 28: 752-758, 1996.

8) Pawlotsky JM, Roudot-Thoraval F, Simmonds P, et al. Extrahepatic immunologic manifestations in chronic hepatitis $\mathrm{C}$ and hepatitis $\mathrm{C}$ virus serotypes. Ann Intern Med 122: 169-173, 1995.

9) Jorgensen C, Legouffe MC, Perney P, et al. Sicca syndrome associated with hepatitis C virus infection. Arthritis Rheum 39: 1166-1171, 1996.

10) Manns MP. Viruses and autoimmune liver disease. Intervirology 35: 108$115,1993$.

11) Congia M, Clemente MG, Dessi C, et al. HLA class II genes in chronic hepatitis $\mathrm{C}$ virus-infection and associated immunological disorders. Hepatology 24: 1338-1341, 1996.

12) Castenskiold EC, Colvin BT, Kelsey SM. Acquired factor VIII inhibitor associated with chronic interferon-alpha therapy in a patient with haemophilia A. Br J Haematol 87: 434-436, 1994. 